\section{Voies lactées. Dynamique des bassins laitiers, entre globalisation et territorialisation}

Napoléone M, Corniaux C, Leclerc B (eds.), 2015, Cardère éditeur, 313 p. ISBN : 978-2-914053-85-3, http:// cardere.fr/, e-book en accès libre : http://bit.ly/1QgrZIC.

Voici un ouvrage singulier qui traite de la production bovine laitière et de ses évolutions, principalement en rapport à l'ancrage des filières aux territoires et leurs adaptations aux soubresauts induits par la mondialisation des échanges. L'intérêt majeur de l'ouvrage réside d'ailleurs dans la mise en perspective des dynamiques locales de développement laitier et leurs interactions avec les changements générés par l'ouverture des marchés. Un autre point qui attirera sans conteste l'attention du lecteur consiste en la diversité des exemples traités, puisque l'ouvrage rapporte les évolutions récentes de bassins laitiers situés aux quatre coins du monde. En fait, ces études de cas sont le fruit des résultats d'investigations conduites par des équipes du Centre de coopération internationale en recherche agronomique pour le développement (CIRAD) et leurs collaborateurs, à l'extérieur de la France, et des chercheurs de l'Institut national de la recherche agronomique (INRA) pour les terrains situés en France. Les exemples traités se rapportent à l'Afrique subsaharienne (Sénégal), l'Amérique latine (Brésil et Uruguay), l'Asie (Vietnam) et l'Europe (plus particulièrement la France, avec les cas de trois bassins laitiers distincts : le Pélardon des Cévennes, les « Quatre Montagnes » et le Livradois-Forez). Pareille diversité, avec la palette de scénarii qu'elle comporte, aussi bien en termes de ressources nécessaires au développement de l'élevage laitier que des savoir-faire nécessaires à la production locale de préparations lactées typées (surtout fromages, mais aussi lait de boisson), octroie au lecteur la possibilité de se livrer à une analyse comparée des bassins laitiers étudiés, et de leurs atouts et contraintes, moyennant les approches systémiques complexes mises en œuvre par les auteurs.

Chaque exemple de bassin laitier donne lieu à une analyse fine des dynamiques passées et en cours, qui ont influencé ses évolutions et qui risquent de déterminer les enjeux futurs qu'il aura à affronter. Dans un souci de généricité, l'ouvrage revient ensuite sur les possibilités offertes par cette diversité de situations de développement de filières laitières pour livrer une approche méthodologique mettant en œuvre des analyses de trajectoire singulière menant ensuite à l'identification de processus communs aux différents territoires, notamment les changements dans la mise en marché des produits, ainsi que les évolutions des systèmes d'élevage. À cet égard, le poids de la demande alimentaire apparaît comme un élément moteur dans la reconfiguration des bassins laitiers, induisant aussi une diversité des formes de développement des filières. Celle-ci représente d'ailleurs, selon les coordinateurs de l'ouvrage, une voie incontournable pour répondre à la demande mondiale en produits laitiers qui se concentre surtout autour des agglomérations urbaines, mais aussi pour assurer la durabilité desdites filières.

En conclusion, les auteurs insistent sur l'absence d'une voie lactée uniforme et universelle. Celles-ci restent à tracer à l'échelle de chaque région, selon les défis du moment, les atouts de chaque bassin, ses ancrages à son territoire et aux valeurs sociales, environnementales, voire économiques et même politiques qui le caractérisent. En d'autres termes, les processus de mondialisation et de territorialisation ne s'expriment pas de manière identique partout et à tout instant. Avec pareils constats, il est logique de questionner les évolutions à venir des bassins laitiers : jusqu'où la recherche de l'authenticité des goûts et de la typicité des produits pourra-t-elle en influencer l'avenir? L'intensification des pratiques d'élevage fera-t-elle disparaître les identités locales ? L'opinion publique saura-telle accepter des mouvements d'intensification reposant sur des «modèles" de fermes d'élevage avec des milliers de vaches ? Autant de questions pour lesquelles il n'y a pas de réponses figées et qui appellent à des recherches ultérieures, notamment dans d'autres régions avec des types d'élevage différents de ceux rapportés dans l'ouvrage, comme par exemple les situations périurbaines dans des mégapoles de plusieurs millions d'habitants comme Le Caire ou Mexico City, ou le cas des filières laitières à offre atomisée avec des centaines de milliers d'élevages de taille réduite livrant chacun quotidiennement des quantités de lait limitées, comme en Inde, premier producteur mondial de lait.

Au final, il est évident que les démarches de recherche adoptées dans cet ouvrage peuvent être transposées à d'autres filières agricoles (céréales, viandes, etc.) avec une portée mondiale, et elles ouvrent des perspectives d'investigations intéressantes, car relevant des choix des sociétés humaines et des modèles de développement qu'elles adoptent. L'ouvrage se clôt par une postface fort opportune, faisant la part belle à une réflexion philosophique sur le lait (les laits, plutôt...), les hommes et la vie. Ce genre de propos rajoute à l'intérêt des différentes études de cas de bassin laitiers présentées dans cet ouvrage ainsi qu'aux possibles évolutions de l'approvisionnement mondial en lait et en produits lactés, insistant sur leur diversité, à un moment où l'uniformisation des modes de production et de consommation tendent à la faire oublier.

Captivant par l'intensité du voyage qu'il permet au lecteur de réaliser à travers le monde des filières laitières à une échelle globale, intéressant par les méthodes originales et 
transdisciplinaires mobilisées pour l'analyse des bassins d'élevage et de transformation du lait, l'ouvrage s'avère de lecture fort plaisante. Très abondamment illustré de photos et figures qui aident à la compréhension des propos développés, il ne peut qu'attirer l'intérêt de tout type de lecteur, aussi bien le consommateur qui voudrait comprendre l'origine de ce qu'il achète comme produits lactés et leur ancrage territorial, que le chercheur en sciences agronomiques, le géographe ou le vétérinaire, avide de mieux saisir les implications de l'inéluctable développement laitier qui s'annonce à l'échelle planétaire et ses conséquences aux niveaux économique, environnemental, voire politique.

Mohamed Taher Sraïri (mt.srairi@iav.ac.ma) 